itself. This section on the exhibition has its own bibliography and is followed by the names and addresses of all the firms involved and of the individuals attending the meeting.

Secondly, probably more important and certainly less ephemeral, this symposium serves as a progress report for quite a large area of ecology, raising several interesting discussion points. Great advances in sensors, data-loggers and computers suggest that ecology may develop to a point where the ecologist places his magic box in a selected site, and couples it up to a multichannel recorder which is in turn coupled to a computer which will print out the answer.

Before we accept this as likely or desirable, it is worth looking at the difficulties and objections. In general, such environmental measurements will be required for correlation with biological parameters and need not be markedly more precise than these are. The blunderbuss method of recording all possible environmental factors in the hope of finding some biologically meaningful correlation is probably wasteful and unproductive. Siddorn describes this as "a despairing attempt to record everything for which an instrument is available with the cosy feeling that multiple regression analysis in the long winter evenings will sort the wheat from the chaff". Much of the more sophisticated equipment described in this volume has been developed in agricultural situations where variability of the biological parameters is relatively small. In more variable wild habitats, the need is still for a large number of cheap sensors and integrators, measuring only environmental factors thought to be biologically meaningful. Other difficulties discussed include getting sensors small enough to measure environmental factors in the microhabitats of invertebrates and the very practical point raised by Long: "Few meteorological instruments function correctly when it is raining".

This useful volume should at least convince sceptics that ecology can now follow up observation with measurement. Near-automation must not cause us to dispense with observation.

P. J. Newbould

\section{COURSE ON HUMAN POPULATIONS}

\section{Heredity, Evolution and Society}

By I. Michael Lerner. Pp. xvi+307. (Freeman: San Franciseo and London, November 1968). $168 s$.

THERE have been several recent books on human genetics and the evolution of man. Inevitably, they overlap and use much the same material. The same inherited characteristics and the same chromosomal abnormalities are used as examples of pleiotropy, heterozygous advantage and trisomy. Heredity, Evolution and Society repeats, therefore, many of the current facts and theories on human evolution. There are brief chapters on the characteristics of living material, on Darwinism, the fossil record and evolution of man, chromosomes and genetic information, sex determination and mutation.

The justification for more books on human genetics is the individual emphasis and interest that each author brings to the subject. Michael Lerner, well known for his work on population genetics of chickens, has chosen to stress this aspect of genetics in its application to man. The chapters on polygenic inheritance, nature and nurture, population structure, selection and human mating systems should be particularly interesting and helpful to the student coming to the subject for the first time. There is a balanced and easily understandable appreciation of the importance of drift and the founder principle in human populations. There is an interesting assessment of the relative importance of heredity and environment in the development of intelligence and of mental defects. The differences between polygenic inheritance and the interaction of genes and external factors are clearly defined; the differences are further emphasized by the frequent, analysis of examples of one or the other which gradually builds up a convincing picture of the difficulties involved in distinguishing between such situations in human populations. Schizophrenia provides an example of where either polygenes or nature and nurture might fit and the alternative theories are worked out in some detail. The treatment of the origin of inbreeding taboos and assortative mating is provocative.

That a whole chapter should be given to denouncing Lysenkoism seems disproportionate, particularly when so little genetic insight is gained from it. The generous use of space and the method of reasoning in this chapter are in marked contrast to the rest of the book. For example, elsewhere in the book there is a short and sane section on the genetics of the American negro.

The book has grown out of a course in genetics given in the University of California to students of many different faculties. As a book to read or as a text for a university course outside California it has all the disadvantages inherent in this type of American work. The layout may be good when it represents the mixed verbal and visual presentation of a lecture but in book form it is confusing. There are diagrams and text and boxes. The boxes, equivalent, it seems, to footnotes, get in the way of the reading and in some places leave no room for page numbers. The author says that the boxes can be left out of the reading, but it is difficult to do this because of the layout and because there are several places where the text is meaningless if a box is omitted. It is not easy to bring the lecture room directly into readable book form and in this respect the book is a failure for anyone outside the University of California.

The author believes that "the names and identities of the architects of modern genetics and evolutionary theory should form part of the cultural equipment of a university graduate" but he provides no bibliography, limiting himself to a few names and a list of unassignable "credits" at the end of the book. He informs the reader that the "Teacher's Manual accompanying this book contains a bibliography". Perhaps the Teacher's Manual also has an extension to the index because several words such as drift that occur throughout the book are not in the index. No Teacher's Manual accompanied the review copy.

Wilma George

\section{VIRUSES IN PLANT CELLS}

\section{Viruses in Flant Hosts}

Form Distribution and Pathological Effects. By Katherine Esau. (The 1968 John Charles Walker Lectures.) Pp. viii +225 . (University of Wisconsin Press: Madison and London, March 1969.) $\$ 10 ; 95 s$.

AbILity to recognize the characteristic symptoms associated with infection of plants by viruses is an essential qualification for the plant pathologist's trade, yet we know rclatively little of how and why symptoms develop in the ways they do. Perhaps because of the restrictions imposed by conventional light microscopy, study of the anatomy and eytology of plants infected by viruses has, until quite recently, been an unfashionable field and the domain of the few, of whom the author of this book, Emeritus Professor Katherine Esau, is the doyen. An eminent plant anatomist, it would be surprising had she not realized the potential of electron microscopy to reveal the effects of virus infection on cells and to aid solution of some of the baffling problems of identification of sites of virus synthesis in cells and intercellular transport of viruses. With what success she has done so, this book is fair evidence. 